\title{
Pre-exposure prophylaxis for HIV prevention in women: current perspectives
}

\author{
This article was published in the following Dove Press journal: \\ International Journal of Women's Health \\ 31 May 2017 \\ Number of times this article has been viewed
}

\author{
Charlene A Flash' \\ Sannisha K Dale ${ }^{2-4}$ \\ Douglas S Krakower $3,5,6$ \\ 'Section of Infectious Diseases, \\ Department of Medicine, Baylor \\ College of Medicine, Houston, TX, \\ ${ }^{2}$ Massachusetts General Hospital, \\ ${ }^{3}$ Department of Psychiatry, Harvard \\ Medical School, Boston, MA, \\ ${ }^{4}$ Department of Psychology, University \\ of Miami, Coral Gables, FL, ${ }^{5}$ Division \\ of Infectious Diseases, Beth Israel \\ Deaconess Medical Center, ${ }^{6}$ The \\ Fenway Institute, Boston, MA, USA
}

\begin{abstract}
There are $\sim 900,000$ new HIV infections among women every year, representing nearly half of all new HIV infections globally. In the US, nearly one-fifth of all new HIV infections occur among women, and women from racial and ethnic minority communities experience disproportionately high rates of new HIV infections. Thus, there is a need to develop and implement effective HIV prevention strategies for women in the US and internationally, with a specific need to advance strategies in minority communities. Previous studies have demonstrated that oral HIV pre-exposure prophylaxis (PrEP), the use of antiretroviral medications by HIV-uninfected persons to prevent HIV acquisition, can reduce HIV incidence among women who are adherent to PrEP. However, to date, awareness and uptake of PrEP among women have been very limited, suggesting a need for innovative strategies to increase the knowledge of and access to PrEP among women in diverse settings. This narrative review summarizes the efficacy and safety data of PrEP in women, discusses considerations related to medication adherence for women who use PrEP, and highlights behavioral, social, and structural barriers to maximize the effectiveness of PrEP in women. It also reviews novel modalities for PrEP in women which are being developed and tested, including topical formulations and long-acting injectable agents that may offer advantages as compared to oral PrEP and proposes a community-oriented, social networking framework to increase awareness of PrEP among women. If women are provided with access to PrEP and support to overcome social and structural barriers to adhere to PrEP, this prevention strategy holds great promise to impact the HIV epidemic among women in the US and globally.
\end{abstract}

Keywords: HIV, prevention, pre-exposure prophylaxis PrEP, narrative review

\section{Introduction}

Currently, there are 900,000 new HIV infections among women every year globally, representing $47 \%$ of all new HIV infections. ${ }^{1}$ In the US, women comprise $19 \%$ of the 50,000 new HIV infections that occur annually, and striking racial disparities exist, with Black women experiencing one of the highest incidences of HIV among all subpopulations in the US, second only to men who have sex with men (MSM). ${ }^{2}$ Studies have demonstrated that HIV pre-exposure prophylaxis (PrEP), the use of antiretroviral medications by HIV-uninfected persons at risk of acquiring HIV, can greatly decrease HIV incidence among women and other priority populations when taken with high adherence. $^{3-8}$ Thus, implementation of PrEP in women in the US and internationally represents an important public health priority. However, to date, uptake of PrEP among women in the US and other countries has been very limited, ${ }^{9-11}$ suggesting a need to invest in strategies that can increase the access to PrEP in women.

This narrative review summarizes the efficacy and safety data of PrEP in women, discusses important considerations relevant to adherence in this population, outlines
Correspondence: Douglas S Krakower Beth Israel Deaconess Medical Center, I I 0 Francis Street, W/LMOB Suite GB, Boston, MA 02215, USA

Tel +l 6176320758

Email dkrakowe@bidmc.harvard.edu
International Journal of Women's Health 2017:9 39|-40I

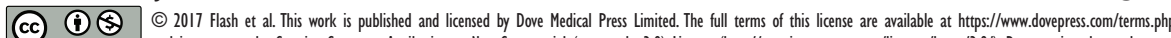
(c). hereby accept the Terms. Non-conmercial uses of the work are permitted without any further permision from Dove Medical Press Limited, provided the work is properly attributed. For permission for commercial use of this work, please see paragraphs 4.2 and 5 of our Terms (https://www.dovepress. com/terms.php). 
behavioral, social, and structural barriers to optimizing PrEP in women, and highlights contextual factors that may influence PrEP implementation in women in domestic and international settings. It also reviews future modalities of PrEP that are being developed and tested for women and proposes a social networking framework for increasing awareness and use of PrEP, thus maximizing its public health benefits, for this underserved priority population.

\section{PrEP efficacy studies}

A number of clinical trials have demonstrated that PrEP is effective in decreasing the risk of HIV transmission to women (Table 1). One of the first studies to provide evidence that PrEP could protect women against acquiring HIV was the TDF2 study by the US Centers for Disease Control and Prevention. ${ }^{4}$ In this study, 1,219 heterosexual men and women in Botswana were randomized to receive a once-daily, oral fixed-dose combination tablet containing tenofovir disoproxil fumarate plus emtricitabine (TDF/FTC) as PrEP or a placebo pill. The study demonstrated a $62 \%$ decrease in HIV incidence among those participants who were assigned to receive PrEP compared to those assigned to receive placebo. In an intention-to-treat analysis of the efficacy of PrEP among 557 women in the study ( $46 \%$ of the study participants), PrEP conferred a $49 \%$ reduction in HIV incidence ( $95 \%$ confidence interval $[\mathrm{CI}]-22 \%$ to $81 \%$ ). Although this subanalysis with female participants did not demonstrate the efficacy of PrEP with statistical significance, this study was not designed to have sufficient statistical power to demonstrate sex-specific efficacy results. An additional subanalysis from TDF2 found that the efficacy of PrEP was 75\% (95\% CI 24\% to 95\%) $)^{4}$ among women who took the PrEP medications as directed, providing evidence that PrEP can protect women against HIV acquisition if they are adherent. ${ }^{4}$

In the Partners PrEP study, the HIV-uninfected members of 4,758 HIV-serodiscordant heterosexual couples in Kenya and Uganda were randomized to receive a daily oral regimen of TDF, TDF/FTC, or placebo; for 38\% of the couples enrolled in this study, the HIV-uninfected partner was female. Enrollment was restricted to couples in whom the HIV-infected partner was not using HIV treatment (ie, they were viremic and thus infectious). In analyses restricted to those couples with HIV-uninfected female partners, the study demonstrated that use of TDF by women reduced their risk of HIV acquisition by $71 \%$ compared to placebo and that use of TDF/FTC reduced their risk of HIV acquisition by $66 \%$; the efficacy of PrEP was similar among men and women, with no statistically significant differences in efficacy by sex. Five of the 45 incident HIV infections that occurred among women during Partners PrEP were diagnosed among participants who were told to discontinue study medications after becoming pregnant or while breastfeeding; 2 of these women were assigned to use TDF and 3 were assigned to use placebo. ${ }^{3}$ Thus, Partners PrEP, in which large numbers of female participants provided sufficient statistical power to detect the efficacy of PrEP among women in particular, demonstrated that TDF-based PrEP can reduce HIV incidence among women if they are sufficiently adherent to PrEP.

Importantly, other studies enrolling exclusively women did not demonstrate the efficacy of TDF-based PrEP, most likely because of suboptimal adherence to study medications among trial participants. For example, in the FEM-PrEP study, in which 2,120 HIV-uninfected women in Kenya, South Africa, and Tanzania were randomized to use TDF/ FTC daily as PrEP or placebo, adherence levels were too low to adequately assess the efficacy of PrEP; analyses of drug levels suggested that $<40 \%$ of women were taking their study medications on a regular basis (Table 1). Notably, adherence may have been low because a majority of women in FEM-PrEP (70\%) considered themselves to have limited HIV risk when they began the study. ${ }^{12}$ Thus, these women may not have perceived a need to take the study medications, particularly because they were told by study investigators that PrEP may or may not offer benefits to them as part of the informed consent process during study enrollment. Similarly, the VOICE study, ${ }^{13}$ in which women were randomized to use TDF, TDF/FTC, or 1\% tenofovir intravaginal gel daily as PrEP, or placebo pills or gels, did not demonstrate the efficacy of PrEP, also presumably because of suboptimal adherence to study product. In VOICE, among women assigned to use oral TDF-based PrEP, $<30 \%$ of plasma samples obtained on a quarterly basis had detectable levels of study drugs. ${ }^{13}$

A meta-analysis of multiple PrEP efficacy studies, including those enrolling women and men and those enrolling only women, found that PrEP was protective across heterogeneous populations, with no difference in effectiveness by sex. ${ }^{14}$ Thus, the preponderance of data suggest that TDF-based PrEP will be protective against HIV acquisition for those women who are able to maintain adequate medication adherence.

\section{PrEP safety data Renal effects}

As the use of TDF for the treatment of HIV infection can have adverse effects on renal function, ${ }^{15,16}$ studies of TDFbased PrEP have examined whether the use of TDF for PrEP is associated with renal adverse effects. These studies have not demonstrated significant differences in rates of 
Table I Efficacy data for HIV PrEP in women

\begin{tabular}{|c|c|c|c|c|c|c|}
\hline Study & Year & Location & No of women enrolled & Regimen(s) tested* & Efficacy for women & Adherence \\
\hline TDF2 ${ }^{4}$ & 2012 & Botswana & 557 & Daily oral TDF/FTC & $\begin{array}{l}49 \%(95 \% \mathrm{Cl}-22 \% \\
\text { to } 81 \%)^{\dagger}\end{array}$ & $\begin{array}{l}\text { Detectable plasma tenofovir } \\
\text { levels in } 80 \% \text { of women who } \\
\text { did not acquire HIV vs } 50 \% \text { of } \\
\text { women who acquired HIV }\end{array}$ \\
\hline Partners PrEP ${ }^{3}$ & 2012 & Kenya, Uganda & $\begin{array}{l}4,758 \text { couples, I,I } 64 \text { with } \\
\text { women as HIV-uninfected } \\
\text { partner assigned to use } \\
\text { PrEP ( } 598 \text { assigned to use } \\
\text { TDF, } 566 \text { assigned to use } \\
\text { TDF/FTC) }\end{array}$ & $\begin{array}{l}\text { Daily oral TDF or } \\
\text { TDF/FTC }\end{array}$ & $\begin{array}{l}\text { TDF: } 71 \%(95 \% \mathrm{Cl} \\
37 \% \text { to } 87 \%) \\
\text { TDF/FTC: } 66 \% \\
\text { ( } 95 \% \mathrm{Cl} 28 \% \text { to } 84 \%)\end{array}$ & $\begin{array}{l}\text { Detectable plasma tenofovir } \\
\text { levels in } 83 \% \text { of women who } \\
\text { did not acquire HIV vs } 31 \% \text { of } \\
\text { women who acquired HIV }\end{array}$ \\
\hline FEM-PrEP'2 & 2012 & $\begin{array}{l}\text { Kenya, South } \\
\text { Africa }\end{array}$ & 2,120 & Daily oral TDF/FTC & $\begin{array}{l}6 \%(95 \% \\
\mathrm{Cl}-52 \% \text { to } 41 \%)\end{array}$ & $\begin{array}{l}\text { Detectable plasma levels } \\
\text { tenofovir in }<40 \% \text { of women }\end{array}$ \\
\hline $\mathrm{VOICE}^{13}$ & 2015 & $\begin{array}{l}\text { South Africa, } \\
\text { Uganda, } \\
\text { Zimbabwe }\end{array}$ & 5,029 & $\begin{array}{l}\text { Daily oral TDF or } \\
\text { TDF/FTC, or daily } \\
\text { intravaginal I\% } \\
\text { tenofovir gel }\end{array}$ & $\begin{array}{l}\text { TDF: }-49 \% \\
\text { (95\% Cl }-129 \% \text { to } 3 \%) \\
\text { TDF/FTC: }-4 \% \\
(95 \% \mathrm{Cl}-50 \% \text { to } 27 \%) \\
\text { Tenofovir gel: } 15 \% \\
(95 \% \mathrm{Cl}-21 \% \text { to } 39 \%)\end{array}$ & $\begin{array}{l}\text { Detectable plasma levels in } \\
30 \% \text { of women assigned to } \\
\text { oral TDF and } 29 \% \text { of women } \\
\text { assigned to oral TDF/FTC. } \\
41 \% \text { of women assigned to } \\
\text { tenofovir gel had no tenofovir } \\
\text { detected in any vaginal samples }\end{array}$ \\
\hline CAPRISA- $004^{77}$ & 2010 & South Africa & 889 & $\begin{array}{l}\text { Pericoital intravaginal } \\
1 \% \text { tenofovir gel }\end{array}$ & $\begin{array}{l}39 \%(95 \% \mathrm{Cl} 6 \% \text { to } \\
60 \%)\end{array}$ & $\begin{array}{l}54 \% \text { efficacy when adherence } \\
>80 \% \text {; } 38 \% \text { efficacy when } \\
\text { adherence } 50 \%-80 \% ; 28 \% \\
\text { efficacy when adherence }<50 \%\end{array}$ \\
\hline FACTS- $001^{78}$ & 2015 & South Africa & 2,029 & $\begin{array}{l}\text { Pericoital intravaginal } \\
1 \% \text { tenofovir gel }\end{array}$ & $\begin{array}{l}0 \%(95 \% \mathrm{Cl}-40 \% \text { to } \\
30 \%)\end{array}$ & $\begin{array}{l}\text { I3\% of women with consistent } \\
\text { use of gel ( } \geq 80 \% \text { of sex acts). } \\
22 \% \text { of women with tenofovir } \\
\text { detected in cervicovaginal } \\
\text { samples at all quarterly visits; } \\
\text { detectable levels of tenofovir } \\
\text { associated with } 52 \% \text { efficacy }\end{array}$ \\
\hline ASPIRE $^{79}$ & 2016 & $\begin{array}{l}\text { Malawi, } \\
\text { South Africa, } \\
\text { Uganda, } \\
\text { Zimbabwe }\end{array}$ & 2,629 & $\begin{array}{l}\text { Monthly intravaginal } \\
\text { ring (DPV) }\end{array}$ & $\begin{array}{l}27 \%(95 \% \mathrm{Cl} \\
1 \% \text { to } 46 \%) \\
(56 \% \text { risk } \\
\text { reduction among } \\
\text { women }>21 \text { years) }\end{array}$ & $\begin{array}{l}\text { Drug levels in } 82 \% \text { of plasma } \\
\text { samples and } 84 \% \text { of returned } \\
\text { rings consistent with use of } \\
\text { intravaginal rings. Lowest levels } \\
\text { of adherence and no efficacy } \\
\text { demonstrated among women } \\
<2 \text { I years old }\end{array}$ \\
\hline The Ring Study ${ }^{80}$ & 2016 & $\begin{array}{l}\text { South Africa, } \\
\text { Uganda }\end{array}$ & 1,959 & $\begin{array}{l}\text { Monthly intravaginal } \\
\text { ring (DPV) }\end{array}$ & $\begin{array}{l}31 \%(95 \% \mathrm{Cl} 1 \% \\
\text { to } 51 \%)\end{array}$ & $\begin{array}{l}\text { Drug levels in } 83 \% \text { of plasma } \\
\text { samples and } 84 \% \text { of returned } \\
\text { rings consistent with use of } \\
\text { intravaginal rings. } 38 \% \text { efficacy } \\
\text { among women }>21 \text { years old; } \\
\text { no efficacy among women } \\
\leq 21 \text { years old. } 65 \% \text { efficacy } \\
\text { when } \leq 20 \mathrm{mg} \text { residual } \\
\text { dapivirine in ring }\end{array}$ \\
\hline $\begin{array}{l}\text { Bangkok } \\
\text { Tenofovir Study }\end{array}$ & 2013 & Thailand & 489 & Daily oral TDF & $\begin{array}{l}79 \%(95 \% \mathrm{Cl} 17 \% \\
\text { to } 97 \%)\end{array}$ & $\begin{array}{l}66 \% \text { of women with detectable } \\
\text { plasma TDF }\end{array}$ \\
\hline
\end{tabular}

Notes: *All studies represent placebo-controlled efficacy trials. ${ }^{\dagger}$ The small number of study endpoints among women participants limited the statistical power to detect significant effect sizes for women.

Abbreviations: TDF, tenofovir disoproxil fumarate; FTC, emtricitabine; DPV, dapivirine; PrEP, pre-exposure prophylaxis; Cl, confidence interval.

serious adverse renal events among participants using PrEP or placebo. In TDF2 and Partners PrEP, rates of elevations in creatinine, a marker of renal function, were not different among women using TDF-based PrEP or placebo. ${ }^{3,4}$ However, a meta-analysis of 10 studies of TDF-based PrEP, including studies that enrolled male and female participants (eg, TDF2 and Partners PrEP), suggested that the use of TDF-based PrEP compared to placebo for males and females combined was associated with a modest but statistically significant decline in renal function. ${ }^{17}$ Although these modest changes in renal function associated with PrEP use were of uncertain clinical significance and tended to resolve with 
discontinuation of PrEP, these findings suggest that it will be important to collect long-term renal safety data for women who use PrEP in clinical settings.

\section{Bone mineral density}

TDF, in addition to its potential effects on renal function, has been associated with reversible decreases in bone mineral density when used for HIV treatment. ${ }^{18}$ Proposed mechanisms for these observed changes include the effect of TDF on bone metabolism or on renal tubular dysfunction, which in turn could possibly alter the rates of bone resorption. In the VOICE trial, a study in which 5,029 young African women were randomized to receive oral or topical TDF-based PrEP or placebo, ${ }^{13}$ adherent participants (ie, those with TDF detected in plasma samples for at least $75 \%$ of their study visits) experienced a decrease of bone mineral density from baseline to 48 weeks in their total hip $(0.9 \%, P=0.018)$ and lumbar spine $(1.4 \%, P=0.002)$ sites on dual-energy x-ray absorptiometry (DEXA) scans. Upon cessation of PrEP, participants regained bone mineral density. In VOICE, even those participants with limited TDF exposure, due to suboptimal study drug adherence, had evidence of decreased bone mineral density compared to placebo. Similar decreases in bone mineral density at the forearm, hip, and lumbar spine occurred in the TDF2 trial as well. ${ }^{19}$ These findings suggest that even low doses of TDF may impact bone health. As no pathologic fractures occurred in these studies ${ }^{4,19}$ and there were no differences in rates of traumatic fractures between placebo and intervention arms in VOICE, ${ }^{19}$ the clinical significance of the changes in bone mineral density as detected in this study are of unclear clinical significance. Nonetheless, as with renal safety, it will be necessary to collect long-term safety data related to bone health for women who use PrEP.

\section{Other safety and tolerability issues}

TDF and FTC have been associated with elevated serum liver enzymes when used for HIV treatment. ${ }^{20}$ An efficacy study of TDF-based PrEP for African women, the FEM-PrEP study, reported small increases in levels of serum liver enzymes (ie, grade 1 or 2) among participants assigned to use PrEP $(\sim 11 \%$ with enzyme changes) compared to placebo $(\sim 9 \%$ with enzyme changes), and in particular among those women who also had prior hepatitis B exposure. ${ }^{21}$ No differences in serious adverse hepatic events were observed between participants assigned to use PrEP or placebo. These results suggest that clinicians who prescribe PrEP to women with risk factors for liver disease, including women with hepatitis B exposure, may need to monitor for evidence of hepatic inflammation. As TDF and FTC are both active against hepatitis B virus, the use of these medications for PrEP by women with chronic hepatitis B will also treat their hepatitis B infections, and the abrupt withdrawal of hepatitis B treatment can rarely result in severe hepatic inflammation. ${ }^{22}$ Thus, clinicians who prescribe PrEP for women have to document their hepatitis B status prior to initiating PrEP, as recommended in clinical guidelines for PrEP. ${ }^{23}$

TDF-based PrEP is generally well-tolerated, though in TDF2 and other PrEP studies, a self-limited "start-up syndrome" of nausea, vomiting, and dizziness that usually resolved during the first month of PrEP use was observed in a minority of participants. ${ }^{4}$ Patients who initiate PrEP may benefit from counseling about this start-up syndrome, so that they are aware that these side effects tend to resolve with persistent use of PrEP and that these side effects are not known to cause long-term harms.

\section{Clinical pharmacology and adherence for PrEP}

The pharmacology of TDF and FTC in the female genital compartments, and its bearing on levels of adherence needed to achieve protection against viral acquisition, is relevant for translating the results of efficacy studies into clinical use of PrEP. Sex hormones, such as estradiol, may impact intracellular concentrations of tenofovir diphosphate (the active metabolite of TDF) in epithelial cells and fibroblasts, creating a gradient in the female reproductive tract in which epithelial cells have higher drug concentrations than do fibroblasts, CD4-positive T cells or macrophages. ${ }^{24}$ Pharmacologic modeling suggests that at-risk women may need to take at least 6 doses of oral TDF/FTC per week to achieve drug levels of tenofovir in the female genital mucosa that can effectively block HIV transmission. ${ }^{25}$ In contrast, women can achieve colorectal tissue levels that seem to be adequate for protection against acquiring HIV with only 2 or 3 doses per week, because tissue concentrations of tenofovir are many-fold greater in the rectal compartment compared to the cervicovaginal compartment with daily oral dosing of TDF. Therefore, the minimum threshold of adherence needed to achieve protective efficacy for women who engage in receptive vaginal intercourse is likely to be substantially higher than that for people who only engage in anal intercourse, though pharmacologic correlates of protection from HIV acquisition are not fully understood for PrEP. Because of the need for consistently high adherence to PrEP for women to achieve protection, robust adherence support will be important to maximize the benefits of PrEP for women. ${ }^{26}$ 
Supports may include counseling, advising women to link their pill-taking behaviors with consistent daily routines, reminder tools (such as alarms or visual triggers), partner awareness and support (for those women in supportive partnerships), and interventions to help at-risk women recognize their risk for HIV infection.

\section{Antiretroviral drug resistance}

One potential unintended consequence of using PrEP with suboptimal adherence is the opportunity for the emergence of drug-resistant viral strains, which can occur if drug concentrations are too low to achieve complete inhibition of viral replication but are sufficiently high to select for drugresistant HIV quasi-species. In clinical studies, some women were infected with HIV while using 4-5 tablets of TDF/FTC per week, though very few of these women developed drugresistant HIV related to their PrEP medication exposure. ${ }^{27}$ Patients who are infected while using TDF/FTC as PrEP with suboptimal adherence could also be at risk for transmitted drug resistance (ie, becoming infected with viral strains that already carry resistance mutations). In efficacy studies of PrEP, rates of drug resistance mutations that were presumed to be transmitted were not different among women assigned to use PrEP compared to those assigned to use placebo. ${ }^{27}$ Overall, these studies offer some evidence that women who are infected with HIV while using PrEP with suboptimal adherence may not be at increased risk for being diagnosed with or disseminating drug-resistant HIV. However, these studies need to be interpreted with caution, as there are very limited data regarding the risk of emergent drug resistance with PrEP at this time.

\section{Conception, pregnancy, and breastfeeding}

Limited data exist about the safety of PrEP use during conception and pregnancy, as women in efficacy studies of PrEP were encouraged to use contraception and they were told to discontinue PrEP if they became pregnant during the study. For example, in the TDF2 trial, most participants (95\%) were using female hormonal contraception at the time of enrollment in the study, with 59\% using oral contraceptives, 53\% using an injectable agent or a long-acting implant, and $<1 \%$ using an alternative method such as intrauterine device or bilateral tubal ligation. ${ }^{4}$ In addition, free condoms were provided to the study participants, and the participants were encouraged to use condoms as part of preventive health counseling. Nonetheless, $18 \%$ of women became pregnant during this study, with no difference in pregnancy rates observed among those assigned to use PrEP and those assigned to placebo. In the FEM-PrEP study, similar rates of pregnancies occurred in the group of women assigned to use PrEP and the group assigned to placebo, and no differences were observed between these 2 groups in rates of adverse birth outcomes, infant growth, or fetal loss. ${ }^{28}$ The Partners PrEP study reported similarly reassuring data about birth outcomes among women who became pregnant during the study. ${ }^{28}$

Whether PrEP use impacts fertility is unknown, though studies with HIV-infected women who are exposed to TDF and/or FTC during conception have not observed an impact on fertility. ${ }^{3,4,12}$ In terms of fetal harms from maternal use of PrEP, TDF and FTC are considered pregnancy category B, that is, unlikely to be teratogenic based on animal data or uncontrolled studies in humans. Observational data suggest that slight growth restriction can occur among infants born to HIV-infected mothers taking TDF during pregnancy, ${ }^{29}$ though the Partners PrEP study found no impact on birth outcomes or infant growth among HIV-uninfected women who used TDF early in pregnancy. ${ }^{28}$ Additional data on the safety of PrEP use for women who are pregnant or who conceive while using PrEP are needed, though, as the number of pregnant women in clinical studies of PrEP has been limited.

Although efficacy studies of PrEP have tested continuous daily dosing of PrEP, oral PrEP could also be used intermittently to reduce the risk of HIV transmission during attempts to conceive among women with HIV-infected male sexual partners. If the HIV-infected male partner of a woman seeking conception receives HIV treatment and achieves virologic suppression, which can greatly reduce his infectiousness, ${ }^{30}$ modeling studies suggest that by using PrEP, there may be limited additional protective benefit for the woman. ${ }^{31}$ However, in "real world" applications of PrEP during clinical care, women may be unaware of whether their partners have achieved virologic suppression, and some women may have partners who may not be on antiviral treatment. In one series of 26 HIV-uninfected women in HIV-serodiscordant relationships with men, for example, $27 \%$ of these women reported that their partners were not taking antiviral treatment, and $58 \%$ of these women either did not know their partners' viral load status or knew that their partner was viremic. ${ }^{32}$ For these women, PrEP could provide a means to be protected from HIV acquisition while attempting to fulfill their fertility desires. For women opting to utilize PrEP during attempts at conception or during pregnancy, it is recommended that their clinicians report their PrEP use to the Antiretroviral Pregnancy Registry, a repository for 
clinical safety data relating to the use of HIV medications, ${ }^{33}$ to facilitate the accrual of post-marketing safety data.

A pharmacokinetic study suggests that women can safely breastfeed their infants while using PrEP. ${ }^{34}$ In this study, investigators measured infant exposure to tenofovir or FTC during breastfeeding by women who were using PrEP. This study demonstrated that high maternal plasma levels of these drugs, which are suggestive of consistent adherence to PrEP, were associated with nominal amounts of tenofovir in breast milk and generally undetectable tenofovir concentrations in infant plasma. Unlike tenofovir, FTC achieves concentrations in breast milk that are comparable to maternal plasma concentrations. However, the amount of FTC detected in the plasma of breastfeeding infants in this study was less than $1 \%$ of what would be considered a safe and therapeutic pediatric dose for this medication, suggesting that the risk of harms to infants who breastfeed from women who use PrEP is likely to be low.

\section{Behavioral health issues}

With the preponderance of evidence suggesting that PrEP is safe and effective for women when used with high levels of adherence, an important question is how to address barriers to adherence that may exist for women at risk for HIV infection, such as behavioral health conditions. There is a high prevalence of mental health issues among women at risk for HIV. For instance, researchers have noted that over $60 \%$ of women at risk and with HIV have histories of trauma/abuse (eg, sexual assault, physical abuse, and domestic violence). ${ }^{35}$ Consistent with the high rates of trauma, researchers estimated a $30 \%$ rate of posttraumatic stress disorder (PTSD, 5 times national rates) among women with HIV in the US. ${ }^{36}$ PTSD is a psychological disorder that results from exposure to trauma and the core symptoms include re-experiencing the traumatic event (eg, flashbacks), avoidance of traumarelated thoughts or reminders, negative thoughts or feelings (eg, overly negative thoughts about the self), and increased arousal or reactivity (eg, hypervigilance and destructive behaviors). ${ }^{37}$ While sometimes linked to trauma histories, but not always, women at risk for HIV often struggle with mood disorders such as depression ${ }^{38}$ and substance abuse disorders. ${ }^{39}$

Substance use, PTSD, and depression have all been associated with sexual risk behaviors (eg, condomless sex).$^{40}$ Ideally, therefore, women with these diagnoses would consult health providers, who would be knowledgeable of these associations and provide women with information on and access to PrEP. Substance use may impair one's decision-making process or efficacy during a sexual encounter. ${ }^{41}$ Similarly, women with PTSD (as a result of a sexual or physical assault) may experience symptoms (eg, flashbacks, hyperarousal, dissociation, and numbing) that limit their ability to be fully present and negotiate safe practices during sex. ${ }^{37}$ Hallmark symptoms of depression include neglecting self-care and negative thoughts about self-worth, ${ }^{37}$ and these may influence a woman's frame of mind to care for her sexual health.

As awareness and use of PrEP among women in the US have been very limited, ${ }^{9}$ the literature on the associations (or impact) of PTSD, depression, and substance use with PrEP adherence is also very limited. ${ }^{42}$ However, existing literature shows strong associations between HIV medication nonadherence and PTSD symptoms, depression, and substance use among women with HIV. ${ }^{43-46}$ With caution, it may be appropriate to consider that PTSD, depression, and/or substance use may influence whether a woman at risk for HIV seeks out PrEP as well as her ability to remain adherent in the context of unaddressed mental health issues.

\section{Social and structural issues}

Beyond the behavioral health issues at the individual level, social and structural issues may impact the uptake and adherence of PrEP among women. In the US, Black women are at the highest risk for contracting HIV in comparison with women of other racial/ethnic groups. ${ }^{47}$ The lives of Black women may be impacted by racism, poverty, unstable housing, unemployment, food insecurity, lack of adequate health insurance, intimate partner violence (IPV), and gender roles, ${ }^{48-50}$ which may directly and indirectly influence their uptake and adherence to PrEP. For instance, Calabrese et al ${ }^{51}$ found a measurable implicit (ie, subconscious) bias among medical students in perceiving Black patients compared to Whites as more likely to have increased engagement in condomless sex if prescribed PrEP. By presenting hypothetical patient scenarios to these medical students in which only patient race was varied, the investigators also demonstrated that these students were less willing to prescribe PrEP to Black patients than to Whites, suggesting a need to train providers in culturally competent sexual health care. Due to years of exposure to racism, women may also have mistrust toward PrEP, providers, and medical institutions..$^{52,53}$ However, Wingood et $\mathrm{al}^{54}$ found that African-American women were more likely than White women to report potential use of PrEP and use of PrEP if recommended by a healthcare provider; hence, providers should be encouraged to discuss PrEP with women of color in their practices. 
In addition, poverty and lack of adequate health insurance may limit women's access to information about PrEP and high-quality health care and limit their ability to afford PrEP ${ }^{55,56}$ Other social factors connected to poverty such as unemployment, unstable housing, and food insecurity may render accessing PrEP and taking PrEP as unimportant if women are unable to fulfill their basic needs for food and shelter. ${ }^{57}$ These diverse social and structural barriers to optimizing PrEP for women suggest a need for comprehensive, culturally tailored, and multifaceted strategies to support PrEP access and use by women.

The primary route of HIV transmission for women is heterosexual contact, and IPV from men places women at increased risk for HIV acquisition, as IPV limits their power and control to negotiate safe sexual practices. ${ }^{58,59}$ Because women can use PrEP in a manner that is concealed from their sexual partners, PrEP offers women autonomy over their sexual health, without the barriers they may face in attempting to negotiate other forms of safe sex with their partners (eg, condom use). ${ }^{6}$ However, IPV may still play a role in the context of PrEP because it may limit a woman's access to money, her mobility to go to medical visits, and her ability to take PrEP consistently if she needs to hide it from her abuser. In addition, a woman may not prioritize taking PrEP given the ongoing risks of IPV to her physical and emotional well-being. ${ }^{60}$

Women are also subjected to prescribed gender roles such as prioritizing the needs of others (ie, children, partners, and family) over their own and silencing their voices in relationships (eg, with partners, family, and providers). ${ }^{61}$ Among women with HIV, self-silencing and prioritizing the needs of others have been linked with medication nonadherence and mental health symptoms (ie, depression). ${ }^{50,61}$ For women at risk for HIV, self-silencing and prioritizing others' needs may be unhelpful if women need to self-advocate to obtain PrEP and to self-prioritize in order to take pills consistently. Interventions to empower women toward greater self-care in the context of sexual health and HIV prevention could enhance the benefits of PrEP for women.

\section{Age-related issues}

Women across the age continuum may benefit from interventions that may empower them to use PrEP, as both young and older women report high interest and willingness in using PrEP. ${ }^{54,62,63}$ Young women in particular may benefit from interventions to help them accurately perceive their risk of HIV acquisition and thus the benefits of using PrEP: one study found that young women did not report higher potential for PrEP uptake or adherence compared to older women despite being at higher risk for HIV. ${ }^{64}$ However, among young adult women in the US, PrEP acceptability has been positively associated with being Black and having a history of transactional sex, ${ }^{65}$ which suggests that some women who are most likely to benefit from using PrEP may be receptive to initiating PrEP if it is made available to them. In addition to potential differences in interest in using PrEP among women across the age continuum, there may be pertinent biological considerations relating to PrEP use by women of different ages. For older women, pertinent biological issues include whether low bone mineral density in the setting of perimenopause could potentially increase the risk of adverse bone-related outcomes associated with PrEP use, ${ }^{19}$ and whether hormonal shifts with age might affect the efficacy of PrEP. Currently, though, these and other age-related biological factors that may affect the safety and efficacy of PrEP for women of varying ages remain underexplored in the current literature.

\section{Domestic and international contexts}

Similar to the US, the group of women who are most at risk for HIV internationally are Black women both on the African continent and in the diaspora (eg, in the Caribbean). Factors such as poverty and IPV are core drivers of the HIV epidemic among women and girls globally and may impede access and adherence to PrEP. ${ }^{65-67}$ For instance, Roberts et $\mathrm{al}^{68}$ found that IPV (encompassing physical, economic, and verbal violence) was significantly associated with low PrEP adherence among HIV-uninfected women with HIV-infected partners in Kenya and Uganda. While existing international literature is lacking on the associations between poverty and PrEP uptake and adherence, given its noted association with HIV testing, access to ART, and adherence, ${ }^{57}$ poverty likely has a similar relationship with PrEP among women internationally. From a very practical stance, women of lower socioeconomic status may be unable to afford PrEP, medical visits, and related transportation costs unless governments and other organizations that provide care to women internationally are willing and able to invest in programs that advance PrEP use for these marginalized women. In addition, using one's limited financial resources for basic needs such food and shelter may take precedence over PrEP, underscoring the need for robust societal investments in PrEP programs.

\section{Raising awareness of PrEP}

In addition to social programs to make PrEP available for women, culturally tailored public health campaigns to raise awareness of PrEP among women could potentially 
accelerate PrEP implementation for women. Because PrEP is a biomedical intervention that requires a prescription, it might reasonably be presumed that many women would learn about PrEP from their healthcare professionals. However, the limited awareness of PrEP that exists among women and their healthcare providers, ${ }^{69}$ despite the availability of PrEP as a US Food and Drug Administration-approved medication for $\sim 5$ years, ${ }^{70}$ suggests that additional efforts to disseminate information about PrEP outside of care settings are needed. Social marketing campaigns and other approaches that leverage community-led communication networks, such as social media networks created by and for women, could provide a means to spread accurate information about PrEP in a manner that is accessible, trustworthy, and empowering for women. Thus, there is an opportunity, if not a responsibility, for government agencies, advocacy organizations, and pharmaceutical companies that manufacture PrEP to invest in socially responsible campaigns that can increase the awareness of PrEP among women and their providers.

\section{Galvanizing the power of community-based organizations}

While raising awareness of PrEP via marketing campaigns is important, engaging community-based organizations and service providers is essential to the dissemination of knowledge about PrEP and PrEP uptake. Women who may be at risk for HIV may not be accessing hospitals or clinics unless they have a health condition that warrants engagement. However, community-based organizations with the trust of the community and reputations for high-quality sexual health initiatives are strategically suited to help promote PrEP awareness and uptake. For instance, SisterLove, Inc. is a reproductive and sexual health organization in Georgia, USA, that focuses on women of African descent. ${ }^{71,72}$ This organization has been hosting free community events aimed at increasing PrEP awareness in a social atmosphere with an outdoor film screening, food, conversations, and HIV/STI testing. ${ }^{73}$ Beyond established community based organizations such as SisterLove, community-based businesses (eg, hair salons and laundromats) that offer a wide range of services to marginalized women may serve as nontraditional yet important gateways ${ }^{74}$ for increasing PrEP awareness, screening, and linkage to providers prescribing PrEP.

\section{The future of PrEP}

The only modality of PrEP that is currently available for clinical use by women is daily oral PrEP. However, the evolution of contraceptive modalities for women over the past several decades offers a glimpse of how PrEP is likely to evolve for women in the future. Contraception for women began with oral pills as a singular option over 50 years ago and later expanded to include a diverse array of delivery options, including topical, injectable, and implantable modes of delivery. ${ }^{75,76}$ For PrEP, studies with topical intravaginal gels containing tenofovir, used either once-daily or in a pericoital manner (ie, before and after sex), have provided conflicting results about the efficacy of this product for reducing HIV incidence. . $^{3,77,78}$ However, 2 additional studies have demonstrated that an intravaginal ring that elutes the antiretroviral medication dapivirine can reduce HIV incidence among women when used with high adherence $^{79,80}$ (Table 1) highlighting that locally delivered forms of PrEP can be effective. Ongoing studies are testing whether long-acting injectable formulations of PrEP, such as injections that can be administered every 2 months, which could facilitate adherence, are efficacious among women and other priority populations. ${ }^{81}$ Future studies will also test whether multimodal delivery methods, such as intravaginal rings that contain antiretroviral medications for PrEP as well as contraceptive medications, ${ }^{82}$ can meet several preventive health needs of women at once in a well-tolerated, userfriendly, and woman-controlled manner to reduce not only HIV incidence but also rates of unintended pregnancies.

\section{Conclusion}

While awaiting the development of new modalities for using PrEP, more attention needs to be devoted to characterizing and addressing gaps in knowledge, access, use, and adherence to PrEP among women in the US and other nations where PrEP is available. Given glaring racial disparities in HIV incidence among women in the US, with Black women experiencing disproportionately high rates of new HIV infections and, paradoxically, some of the greatest social and structural barriers to accessing PrEP, there is a critical need for additional investment in research and implementation of PrEP for women of color. Using the principles of community-based participatory research and community activism, researchers and advocates will need to discover ways to ignite a new level of engagement among individual women, healthcare providers, and governmental organizations to optimize PrEP implementation for women. If effective and socially responsible marketing campaigns can be deployed to raise awareness of PrEP more broadly, and if there is political will to invest in programs to make PrEP accessible and affordable for women, then PrEP could have a substantial impact on the HIV epidemic among women in the US and globally. 


\section{Acknowledgments}

Dr Flash was supported by NIMH K23 MH109358, Dr Dale was supported by NIMH K23 MH108439, and Dr Krakower was supported by NIMH K23 MH098795.

\section{Disclosure}

Dr Flash has received investigator-initiated research funds from and served on the scientific advisory board for Gilead Sciences. Dr Krakower has participated in research with unrestricted funding from Gilead Sciences, has received royalties as an author for UptoDate, Inc., and has received honoraria for authorship from Medscape and MED-IQ. The authors report no other conflicts of interest in this work.

\section{References}

1. UNAIDS. AIDSinfo. Available from: http://aidsinfo.unaids.org/. Accessed February 3, 2017.

2. Centers for Disease Control and Prevention. Diagnoses of HIV infection in the United States and dependent areas; 2015. Available from: https://www.cdc.gov/hiv/statistics/overview/ataglance.html. Accessed April 5, 2017.

3. Baeten JM, Donnell D, Ndase P, et al. Antiretroviral prophylaxis for HIV prevention in heterosexual men and women. N Engl J Med. 2012; 367(5):399-410.

4. Thigpen MC, Kebaabetswe PM, Paxton LA, et al. Antiretroviral preexposure prophylaxis for heterosexual HIV transmission in Botswana. N Engl J Med. 2012;367(5):423-434.

5. Grant RM, Lama JR, Anderson PL, et al. Preexposure chemoprophylaxis for HIV prevention in men who have sex with men. NEngl JMed. 2010;363(27):2587-2599.

6. Choopanya K, Martin M, Suntharasamai P, et al. Antiretroviral prophylaxis for HIV infection in injecting drug users in Bangkok, Thailand (the Bangkok Tenofovir Study): a randomised, double-blind, placebocontrolled phase 3 trial. Lancet. 2013;381(9883):2083-2090.

7. McCormack S, Dunn DT, Desai M, et al. Pre-exposure prophylaxis to prevent the acquisition of HIV-1 infection (PROUD): effectiveness results from the pilot phase of a pragmatic open-label randomised trial. Lancet. 2016;387(10013):53-60.

8. Molina JM, Capitant C, Spire B, et al. On-demand preexposure prophylaxis in men at high risk for HIV-1 infection. N Engl J Med. 2015; 373(23):2237-2246.

9. Bush S, Magnuson D, Rawlings K, Hawkins T, McCallister S, Mera Giler R. Racial characteristics of FTC/TDF for pre-exposure prophylaxis (PrEP) users in the US. ASM Microbe Conference; June 16-20, 2016; Boston.

10. Mera R, McCallister S, Palmer B, Mayer G, Magnuson D, Rawlings K. Truvada (TVD) for HIV pre-exposure prophylaxis (PrEP) utilization in the United States (2013-2015). 21st International AIDS Conference; July 18-22, 2016; Durban, South Africa.

11. Smith DK, Van Handel M, Wolitski RJ, et al. Vital signs: estimated percentages and numbers of adults with indications for preexposure prophylaxis to prevent HIV acquisition - United States, 2015. MMWR Morb Mortal Wkly Rep. 2015;64(46):1291-1295.

12. Van Damme L, Corneli A, Ahmed K, et al. Preexposure prophylaxis for HIV infection among African women. $N$ Engl J Med. 2012;367(5): 411-422.

13. Marrazzo JM, Ramjee G, Richardson BA, et al. Tenofovir-based preexposure prophylaxis for HIV infection among African women. $N$ Engl JMed. 2015;372(6):509-518.

14. Fonner VA, Dalglish SL, Kennedy CE, et al. Effectiveness and safety of oral HIV preexposure prophylaxis for all populations. AIDS 2016;30(12):1973-1983.
15. Cooper RD, Tonelli M. Renal disease associated with antiretroviral therapy in the treatment of HIV. Nephron Clin Pract. 2011;118(3): c262-c268.

16. Cooper RD, Wiebe N, Smith N, Keiser P, Naicker S, Tonelli M. Systematic review and meta-analysis: renal safety of tenofovir disoproxil fumarate in HIV-infected patients. Clin Infect Dis. 2010; 51(5):496-505.

17. Yacoub R, Nadkarni GN, Weikum D, et al. Elevations in serum creatinine with tenofovir-based HIV pre-exposure prophylaxis: a metaanalysis of randomized placebo-controlled trials. J Acquir Immune Defic Syndr. 2016;71(4):e115-e118.

18. Calmy A, Fux CA, Norris R, et al. Low bone mineral density, renal dysfunction, and fracture risk in HIV infection: a cross-sectional study. J Infect Dis. 2009;200(11):1746-1754.

19. Mirembe BG, Kelly CW, Mgodi N, et al. Bone mineral density changes among young, healthy african women receiving oral tenofovir for HIV preexposure prophylaxis. J Acquir Immune Defic Syndr. 2016;71(3): 287-294.

20. Kovari H, Sabin CA, Ledergerber B, et al. Antiretroviral drugs and risk of chronic alanine aminotransferase elevation in human immunodeficiency virus (HIV)-monoinfected persons: the data collection on adverse events of anti-HIV drugs study. Open Forum Infect Dis. 2016; 3(1):ofw009.

21. Mandala J, Nanda K, Wang M, et al. Liver and renal safety of tenofovir disoproxil fumarate in combination with emtricitabine among African women in a pre-exposure prophylaxis trial. BMC Pharmacol Toxicol. 2014; $15: 77$.

22. Bessesen M, Ives D, Condreay L, Lawrence S, Sherman KE. Chronic active hepatitis B exacerbations in human immunodeficiency virusinfected patients following development of resistance to or withdrawal of lamivudine. Clin Infect Dis. 1999;28(5):1032-1035.

23. US Public Health Service. Preexposure Prophylaxis for the Prevention of HIV Infection inthe United States - 2014: A Clinical Practice Guideline. Available from: http://www.cdc.gov/hiv/pdf/guidelines/ PrEPguidelines2014.pdf. Accessed January 25, 2017.

24. Shen Z, Fahey JV, Bodwell JE, Rodriguez-Garcia M, Kashuba AD, Wira CR. Sex hormones regulate tenofovir-diphosphate in female reproductive tract cells in culture. PLoS One. 2014;9(6):e100863.

25. Cottrell ML, Yang KH, Prince HM, et al. A translational pharmacology approach to predicting outcomes of preexposure prophylaxis against HIV in men and women using tenofovir disoproxil fumarate with or without emtricitabine. J Infect Dis. 2016;214(1):55-64.

26. Corneli A, Perry B, Agot K, Ahmed K, Malamatsho F, Van Damme L. Facilitators of adherence to the study pill in the FEM-PrEP clinical trial. PLoS One. 2015;10(4):e0125458.

27. Grant RM, Liegler T, Defechereux P, et al. Drug resistance and plasma viral RNA level after ineffective use of oral pre-exposure prophylaxis in women. AIDS. 2015;29(3):331-337.

28. Mugo NR, Hong T, Celum C, et al. Pregnancy incidence and outcomes among women receiving preexposure prophylaxis for HIV prevention: a randomized clinical trial. JAMA. 2014;312(4):362-371.

29. Siberry GK, Williams PL, Mendez H, et al. Safety of tenofovir use during pregnancy: early growth outcomes in HIV-exposed uninfected infants. AIDS (London, England). 2012;26(9):1151-1159.

30. Cohen MS, Chen YQ, McCauley M, et al. Prevention of HIV-1 infection with early antiretroviral therapy. $N$ Engl J Med. 2011;365(6): 493-505.

31. Hoffman RM, Jaycocks A, Vardavas R, et al. Benefits of PrEP as an adjunctive method of HIV prevention during attempted conception between HIV-uninfected women and HIV-infected male partners. J Infect Dis. 2015;212(10):1534-1543.

32. Seidman DL, Weber S, Timoney MT, et al. Use of HIV pre-exposure prophylaxis during the preconception, antepartum and postpartum periods at two United States medical centers. Am J Obstet Gynecol. 2016;215(5):632.e1-632.e7.

33. The Antiretroviral Pregnancy Registry. Available from: http:// apregistry.com/. Accessed February 27, 2017. 
34. Mugwanya KK, Hendrix CW, Mugo NR, et al. Pre-exposure prophylaxis use by breastfeeding HIV-uninfected women: a prospective short-term study of antiretroviral excretion in breast milk and infant absorption. PLoS Med. 2016;13(9):e1002132.

35. Cohen M, Deamant C, Barkan S, et al. Domestic violence and childhood sexual abuse in HIV-infected women and women at risk for HIV. Am J Public Health. 2000;90(4):560-565.

36. Machtinger EL, Wilson TC, Haberer JE, Weiss DS. Psychological trauma and PTSD in HIV-positive women: a meta-analysis. AIDS Behav. 2012;16(8):2091-2100.

37. Diagnostic and Statistical Manual of Mental Disorders: DSM-5. Arlington, VA: American Psychiatric Association; 2013.

38. Dale SK, Weber KM, Cohen MH, Kelso GA, Cruise RC, Brody LR. Resilience moderates the association between childhood sexual abuse and depressive symptoms among women with and at-risk for HIV. AIDS Behav. 2015;19(8):1379-1387.

39. W Batchelder A, Lounsbury DW, Palma A, et al. Importance of substance use and violence in psychosocial syndemics among women with and at-risk for HIV. AIDS Care. 2016;28(10):1316-1320.

40. Brown MJ, Masho SW, Perera RA, Mezuk B, Pugsley RA, Cohen SA. Sex disparities in adverse childhood experiences and HIV/STIs: mediation of psychopathology and sexual behaviors. AIDS Behav. 2017;21(6)1550-1566.

41. Scott-Sheldon LA, Carey KB, Cunningham K, Johnson BT, Carey MP Alcohol use predicts sexual decision-making: a systematic review and meta-analysis of the experimental literature. AIDS Behav. 2016; 20(Suppl 1):S19-S39.

42. Mehrotra ML, Glidden DV, McMahan V, et al. The effect of depressive symptoms on adherence to daily oral PrEP in men who have sex with men and transgender women: a marginal structural model analysis of the iPrEx OLE study. AIDS Behav. 2016;20(7): $1527-1534$

43. Dale S, Cohen M, Weber K, Cruise R, Kelso G, Brody L. Abuse and resilience in relation to HAART medication adherence and HIV viral load among women with HIV in the United States. AIDS Patient Care STDS. 2014;28(3):136-143.

44. Machtinger EL, Haberer JE, Wilson TC, Weiss DS. Recent trauma is associated with antiretroviral failure and HIV transmission risk behavior among HIV-positive women and female-identified transgenders. AIDS Behav. 2012;16(8):2160-2170.

45. Sharpe TT, Lee LM, Nakashima AK, Elam-Evans LD, Fleming PL. Crack cocaine use and adherence to antiretroviral treatment among HIV-infected black women. J Community Health. 2004;29(2): $117-127$.

46. Belenky NM, Cole SR, Pence BW, Itemba D, Maro V, Whetten K. Depressive symptoms, HIV medication adherence, and HIV clinical outcomes in Tanzania: a prospective, observational study. PLoS One. 2014;9(5):e95469.

47. Centers for Disease Control and Prevention. Women, gender, HIV by group, HIV/AIDS, CDC. Available from: http://www.cdc.gov/hiv/ group/gender/women/index.html. Accessed February 28, 2017.

48. Stratford D, Mizuno Y, Williams K, Courtenay-Quirk C, O’Leary A. Addressing poverty as risk for disease: recommendations from CDC's consultation on microenterprise as HIV prevention. Public Health Rep. 2008;123(1):9-20.

49. Kelso GA, Cohen MH, Weber KM, Dale SK, Cruise RC, Brody LR. Critical consciousness, racial and gender discrimination, and HIV disease markers in African American women with HIV. AIDS Behav. 2014;18(7):1237-1246.

50. Brody LR, Stokes LR, Kelso GA, et al. Gender role behaviors of high affiliation and low self-silencing predict better adherence to antiretroviral therapy in women with HIV. AIDS Patient Care STDS. 2014;28(9):459-461.

51. Calabrese SK, Earnshaw VA, Underhill K, Hansen NB, Dovidio JF. The impact of patient race on clinical decisions related to prescribing HIV pre-exposure prophylaxis (PrEP): assumptions about sexual risk compensation and implications for access. AIDS Behav. 2014;18(2):226-240.
52. Dale SK, Bogart LM, Wagner GJ, Galvan FH, Klein DJ. Medical mistrust is related to lower longitudinal medication adherence among AfricanAmerican males with HIV. J Health Psychol. 2016;21(7):1311-1321.

53. Underhill K, Morrow KM, Colleran C, et al. A qualitative study of medical mistrust, perceived discrimination, and risk behavior disclosure to clinicians by U.S. male sex workers and other men who have sex with men: implications for biomedical HIV prevention. J Urban Health. 2015;92(4):667-686.

54. Wingood GM, Dunkle K, Camp C, et al. Racial differences and correlates of potential adoption of preexposure prophylaxis: results of a national survey. J Acquir Immune Defic Syndr. 2013;63(Suppl 1): S95-S101.

55. Doblecki-Lewis S, Liu A, Feaster D, et al. Healthcare access and PrEP continuation in San Francisco and Miami following the U.S. PrEP demo project. J Acquir Immune Defic Syndr. 2016;74(5):531-538.

56. Gwadz M, Cleland CM, Kutnick A, et al. Factors associated with recent HIV testing among heterosexuals at high risk for HIV infection in New York City. Front Public Health. 2016;4:76.

57. Cornelius T, Jones M, Merly C, Welles B, Kalichman MO, Kalichman SC. Impact of food, housing, and transportation insecurity on ART adherence: a hierarchical resources approach. AIDS Care. 2017;29(4):449-457.

58. Peasant C, Sullivan TP, Weiss NH, Martinez I, Meyer JP. Beyond the syndemic: condom negotiation and use among women experiencing partner violence. AIDS Care. 2017;29(4):516-523.

59. Mittal M, Senn TE, Carey MP. Fear of violent consequences and condom use among women attending an STD clinic. Women Health. 2013;53(8):795-807.

60. Braksmajer A, Senn TE, McMahon J. The potential of pre-exposure prophylaxis for women in violent relationships. AIDS Patient Care STDS. 2016;30(6):274-281.

61. Brody LR, Stokes LR, Dale SK, et al. Gender roles and mental health in women with and at risk for HIV. Psychol Women Q. 2014; 38(3):311-326.

62. Flash CA, Stone VE, Mitty JA, et al. Perspectives on HIV prevention among urban black women: a potential role for HIV pre-exposure prophylaxis. AIDS Patient Care STDS. 2014;28(12):635-642.

63. Auerbach JD, Kinsky S, Brown G, Charles V. Knowledge, attitudes, and likelihood of pre-exposure prophylaxis (PrEP) use among US women at risk of acquiring HIV. AIDS Patient Care STDS. 2015;29(2):102-110.

64. Rubtsova A, Wingood GM, Dunkle K, Camp C, DiClemente RJ. Young adult women and correlates of potential adoption of pre-exposure prophylaxis (PrEP): results of a national survey. Curr HIV Res. 2013; 11(7):543-548.

65. Garfinkel DB, Alexander KA, McDonald-Mosley R, Willie TC, Decker MR. Predictors of HIV-related risk perception and PrEP acceptability among young adult female family planning patients. AIDS Care. 2016;29(6):751-758

66. Etudo O, Metheny N, Stephenson R, Kalokhe AS. Intimate partner violence is linked to less HIV testing uptake among high-risk, HIVnegative women in Atlanta. AIDS Care. Epub December 21, 2016.

67. Jennings L, Mathai M, Linnemayr S, et al. Economic context and HIV vulnerability in adolescents and young adults living in urban slums in Kenya: a qualitative analysis based on scarcity theory. AIDS Behav. Epub Jan 11, 2017.

68. Roberts ST, Haberer J, Celum C, et al. Intimate partner violence and adherence to HIV pre-exposure prophylaxis (PrEP) in African women in HIV serodiscordant relationships: a prospective cohort study. J Acquir Immune Defic Syndr. 2016;73(3):313-322.

69. Seidman D, Carlson K, Weber S, Witt J, Kelly PJ. United States family planning providers' knowledge of and attitudes towards preexposure prophylaxis for HIV prevention: a national survey. Contraception. 2016; 93(5):463-469.

70. US Food and Drug Administration. Truvada for PrEP Fact Sheet: Ensuring Safe and Proper Use; July 2012. Available at: https://www. fda.gov/downloads/NewsEvents/Newsroom/FactSheets/UCM312279. pdf. Accessed May 23, 2017. 
71. Painter TM, Herbst JH, Diallo DD, White LD. Community-based program to prevent HIV/STD infection among heterosexual black women. MMWR Suppl. 2014;63(1):15-20.

72. Diallo DD, Moore TW, Ngalame PM, White LD, Herbst JH, Painter TM. Efficacy of a single-session HIV prevention intervention for black women: a group randomized controlled trial. AIDS Behav. 2010;14(3): 518-529.

73. SisterLove, Inc. US Women \& PrEP Working Group. Available at: http://www.sisterlove.org/us-women-prep-working-group/. Accessed May 23, 2017.

74. Browne RC. Most Black women have a regular source of hair care-but not medical care. J Natl Med Assoc. 2006;98(10):1652-1653.

75. Myers JE, Ellman TM, Westhoff C. Injectable agents for pre-exposure prophylaxis: lessons learned from contraception to inform HIV prevention. Curr Opin HIV AIDS. 2015;10(4):271-277.

76. Myers JE, Sepkowitz KA. A pill for HIV prevention: deja vu all over again? Clin Infect Dis. 2013;56(11):1604-1612.

77. Abdool Karim Q, Abdool Karim SS, Frohlich JA, et al. Effectiveness and safety of tenofovir gel, an antiretroviral microbicide, for the prevention of HIV infection in women. Science. 2010;329(5996): 1168-1174.
78. Rees H, Delaney-Moretlwe S, Lombard C, et al. Facts 001 phase III trial of pericoital tenofovir 1\% gel for HIV prevention in women. 2015 Conference on Retroviruses and Opportunistic Infections; February 23-26, 2015; Seattle, WA.

79. Baeten JM, Palanee-Phillips T, Brown ER, et al. Use of a vaginal ring containing dapivirine for HIV-1 prevention in women. $N$ Engl J Med. 2016;375(22):2121-2132.

80. Nel A, van Niekerk N, Kapiga S, et al. Safety and efficacy of a dapivirine vaginal ring for HIV prevention in women. N Engl J Med. 2016; 375(22):2133-2143.

81. Whitfield T, Torkington A, van Halsema C. Profile of cabotegravir and its potential in the treatment and prevention of HIV-1 infection: evidence to date. HIV AIDS (Auckl). 2016;8:157-164.

82. AIDS Vaccine Advocacy Coalition. Vaginal Rings: Products in development for HIV prevention and multipurpose technologies; December, 2013. Available from: http://www.avac.org/resource/vaginal-ringsproducts-development-hiv-prevention-and-multipurpose-technologies Accessed May 23, 2017.
International Journal of Women's Health

\section{Publish your work in this journal}

The International Journal of Women's Health is an international, peerreviewed open-access journal publishing original research, reports, editorials, reviews and commentaries on all aspects of women's healthcare including gynecology, obstetrics, and breast cancer. The manuscript management system is completely online and includes

\section{Dovepress}

a very quick and fair peer-review system, which is all easy to use. Visit http://www.dovepress.com/testimonials.php to read real quotes from published authors.

Submit your manuscript here: http://www.dovepress.com/international-journal-of-womens-health-journal 